\title{
Finding the Purpose in Education: Assessing the Goals and Ideals of Education from the Perspective of Canadian Elementary Students
}

\author{
Ellen Marie Hamm ${ }^{1, *} \&$ Edward Griffith ${ }^{2}$ \\ ${ }^{1}$ Education Department, Canisius College, Buffalo, USA \\ ${ }^{2}$ Graduate Childhood Education Candidate, Canisius College, Buffalo, USA
}

Corresponding author: Ellen Marie Hamm, Education Department, Canisius College, 1107 Churchill Tower, 2001 Main Street, Buffalo New York 14208, USA. E-mail: hamme@canisius.edu

Received: August 26, 2012 Accepted: October 7, 2012 Published: November 2, 2012

doi:10.5296/ije.v4i4.2292ＵRL: http://dx.doi.org/10.5296/ije.v4i4.2292

\begin{abstract}
The focus of this action research project was to discern elementary students' views regarding the goal or purpose of their education. Participants included 24 students in a grade four/five split classroom from a middle class neighbourhood in Toronto, Ontario, Canada. Students were asked to voluntarily complete a researcher made survey regarding their perception on education. The survey required the students to reflect on four major areas; school for the purpose of citizenship, school for the purpose of building a better personal future, attitudes toward curriculum, and student attitudes about their own academic performance. The results of this study indicated that students strongly believed that school plays a large role in preparing them for the future and in building citizenship. However, the students expressed a generally negative attitude toward personal academic performance academics and curriculum. Implications for educators are discussed in light of student responses.
\end{abstract}

Keywords: action research; purpose; education; student attitudes 


\section{Historical Perspective}

In Canada, formal education has existed since the early years of the $19^{\text {th }}$ century, and since that time the role of education has continually adapted to fit the changing needs of the Canadian people (Baldwin, 2008). In 1807 Upper Canada (what would later become the province of Ontario) introduced The Grammar School Act, which was the first official government measure on education for this region of Canada (Baldwin, 2008). Shortly afterwards in 1816 common schools were established to provide basic education to all children (Baldwin, 2008). By 1846 power was handed over to a central education authority for Upper Canada and it was at this time that the purpose of school shifted. Schools became public institutions that existed to serve political, economic and social needs of the society (Baldwin, 2008).

\section{Legislation}

Legislation plays a central role in defining what the purposes of school and education are for the province of Ontario. Education in the province of Ontario is dictated and governed by the regulations set forth in The Education Act, R.S.O 1990, Chapter E.2. For the purpose of exploring the goals of modern education, this document served as a baseline for what the ideal of education should resemble.

The current document set forth by the Ontario government outlines all elements of the educational sphere within the province. It encompasses everything from finances, attendance, and organisation of school boards, teacher education, new teacher induction, and curriculum.

\section{Theoretical Perspective}

Jerome Bruner (1996) wrote that education "is a complex pursuit of fitting a culture to the needs of its members, and its members and their ways of knowing to the needs of the culture" (p. 43). In this statement Bruner placed the goal and the purpose of education squarely within a cultural milieu. In an earlier work, Bruner also aligned education with the anthropological idea that changes in culture is directly related to change in thought (Bruner, 1971).

These sentiments are also echoed in a 1959 address Bruner delivered at the Rhode Island College of Education, where he discussed the unique position of teachers and teaching. This speech outlines his theory on the nature of the relationship between teacher and student. For Bruner this relationship hinges on the fact that one of the primary functions of the teacher is to utilise error in an instructive way (Bruner, 2006).

Within the discussion of what the goals of education are, Jerome Bruner provided a unique perspective. His ideas on the purpose of teachers in the classroom, the origins of intellect and education, and the goal of education for society have informed this research. 
The Vygotskian perspective on cognitive development is well aligned with the theories of Jerome Bruner. Vygotsky's theory focuses on the relationship among adults, children, and their culture, and asserts that humans cannot separate the individual from the context and still have a complete understanding of either (Wink \& Putney, 2002). Much like Bruner hypothesized, learning for Vygotsky is a social and cultural phenomenon.

Within his social constructivism theory of learning Vygotsky suggests the learner is much more actively involved in a joint enterprise with the teacher of creating or constructing new meanings (Atherton, 2011). Within the social realm of education, adults work to facilitate an active experience where learning is more than just passively receiving and responding to information (Wink \& Putney, 2002).

In respect to pedagogy, John Dewey provides philosophical insights into the role and purpose of education in society. At the heart of his ideals on education is the desire to place human knowledge into the framework of universal evolution (Parodi, 1951). Similar to Jerome Bruner, Dewey presents a culturally driven outlook on the role of education. In broad terms, Dewey observes that education has the goal of affecting change in an individual as a result of experience (Childs, 1951). Looking further into Dewey's philosophy, Childs writes, "in its narrower, deliberate form, education signifies conscious effort by some organized group to shape the conduct and the emotional and intellectual dispositions of its young" (p. 420). This reflection provides an understanding of what Dewey envisioned as the purpose of education and school. Much like Bruner's thoughts on educational purpose, Dewey also espoused the notion that through education, society is responsible for its own existence and perpetuation (Childs, 1951).

\section{Purpose Statement}

For educators it is important to understand the perspective of their students. As students are the prime beneficiaries of the educational process, their ideals should rightfully be taken into consideration. As well, if the ideals and goals of both students and teachers do not match with what has been politically mandated, then it will be important to understand where the disconnect lies. The purpose of this action research was to examine the goals and ideals of education and schools from the perspective of Canadian elementary school students.

\section{Ideals in Education}

Zenkov, Harmon, and van Lier (2008) explored students' perspective of ideals and purpose in education through a student photography project. This study looked specifically at urban high school students as it aimed to shed light on the connection between high school dropout rates and what the authors refer to as, "an endemic disengagement from formal education" (p.162). The photography and commentary of the students produced in this project provided evidence of the attitudes students have towards schools' purpose. Students showed that they believed that school should allow them to lead a good life, which includes 
happiness, health and meaningful relationships. The study also revealed that students spoke highly of the desire for an education that will ideally prepare them for interesting and consequential employment. From a heightened personal perspective, the students also suggested in their photography that school should help provide them with alternatives in their lives, while ensuring that they have a strong sense of choice.

The results of this study may not be surprising in light of the fact that many in society value education as a means to a better life. The results may lead the reader to question how schools can help students find happiness, health and meaning in life. Perhaps we need to pose these questions to our young students.

\section{School for Society}

Power (2005) states that, "in order to define the purposes of education we must begin by forging a shared vision of the kind of society we wish to create" (p. 13). Through this shared vision, the common theme found here is that the purpose of education becomes circular in its reasoning. Education and schools are institutions built upon ideals, and perpetuated as a means to create a specific set of future ideals. These ideals however may not be aligned for teachers, students, and society.

While arguing that a shared vision of society needs to exist in order to define the purpose of education, Power (2005) relies heavily on United Nations Educational, Scientific and Cultural Organization (UNESCO) initiatives and the 1948 Declaration of Human Rights to build his version of what society should strive to be. In referencing UNESCO, Power highlights our common values and global ethics, which include the principles of democracy, peace, human rights and pluralism. These common values have been jointly determined via UNESCO's Universal Ethics Project (1996), the International Commission on Education for the $21^{\text {st }}$ Century (UNESCO, 1995) and the World Education Fellowship Global Preferred Futures Project (Campbell et al. 2005). Power (2005) argues that education needs to strengthen society while at the same time build individual personalities.

Abowitz (2008) reflects on the need to ensure that education represents the rights and the needs of the citizens of the world. She notes that education should be balanced with the interests of the state, family and individual on one side and on the other side with the individual's right to freedom of conscience and association. Within this argument it is clear that education is inextricably linked to people and their society. Much like Power, Abowitz presents an overwhelming idea that schools function as places to promote and build a sense of common good among students and their families.

\section{Student Perspectives}

Gray and McLellan (2006) astutely observe that within the educational research community there has been an absence of quantitative research investigating student attitudes 
towards school. For the most part, and as is evidenced within this review of literature, the body of research has relied heavily on philosophical precepts.

Tymms (2001) attempted to add to the research base on this topic through a study of Scottish school children. Tymms (2001) looked specifically at the feelings of seven-year-old students in an effort to help schools and teachers better understand their students. The researchers in this study used a monitoring system to assess how students felt about academics, and in general terms, school. This monitoring system tracked the academic achievements of students over a seven-year period while at the same time assessing their attitudes.

In an earlier study, Tymms (1999) (as cited in Gray \& McLellan, 2006) explored very similar issues of student attitudes, and concluded that overall, primary students were very positive about their school experience and the material that was taught to them. Tymms' more recent findings showed similar results and reported that $66 \%$ of students thought of school in a positive light (Tymms, 2001). The data collected during the 2001 study came from student responses to a series of statements. The statements focused on reading, mathematics and school in general, while also assessing overall attitudes and self-concepts of the students. The results from Tymms' $(1999,2001)$ studies draw a distinct parallel between student attitude and academic achievement, where the more success a student had the more favourable their outlook toward school.

Gray and McLellan (2006) undertook a similar study and surveyed 1,310 students from 21 different primary schools in England. The research in this case focused less on academics, as its purpose was to describe information pertaining to perceived gender gaps in overall attitudes towards school. The results of their questionnaire reported no statistically significant difference by gender but resulted in a clear picture of the attitudes of the students surveyed.

Boys and girls alike responded positively in areas such as the difficulty of their schoolwork, feeling included within their school community, the safety of their playground, and receiving positive affirmations from their teachers. The results were less encouraging on items such as their feelings about doing homework, whether students felt clever or not, and if they felt that they had opportunities to do things that they were good at. From the gender perspective presented in this research girls were shown to have generally more positive attitudes about school in a wide range of categories. This pattern has also been supported by studies such as West, Hailes, and Sammons (1997) and Jarvis and Pell (2002).

Thomas et al. (2000) presented a study in which students from Scotland were surveyed in order to explore school effectiveness and improvement while keeping in mind the need to use student attitudes to inform a range of purposes. Their research attempted to provide information that may be related to school culture and ethos, planning, development, and more effective student assessment. All of these factors combine to better evaluate the overall efficacy of schools in Scotland. 
The sample for this study included 1,114 students from 44 different primary schools in Scotland and the student survey concentrated on four key areas: whole school issues, the learning context, self concept and behaviour (Thomas, Smees, MacBeath, Robertson \& Boyd, 2000). These areas were addressed by the researchers in response to a growing desire to listen to the voices of students in Scotland with the goal of using student responses to inform school improvement and eventually, policy. The results of this study support that students were "most positive in relation to the aspects of schooling labelled pupil culture and behaviour and least positive in relation to engagement with school" (p. 291). Similar to Gray and MacLellan (2006) the results also indicate that students were positive in terms of safety in the playground and the difficulty of their work, and negative in terms of their own self-concept (Thomas, Smees, MacBeath, Robertson, \& Boyd, 2000).

In general, the literature related to student perception about schools suggests that even young students are able to form and express their opinion about their education. If we consider society a stakeholder in the educational system, we should not ignore the voice of all in society, especially those most intimately impacted. There exists a continued need for education to be informed by students as well as teachers and adults in society.

\section{Method}

\subsection{Sample and Setting}

The sample for this research proposal was a sample of convenience as this action research was undertaken in conjunction with a student teaching placement. The setting was a moderately sized elementary school within the city of Toronto. The school, which is located within a middle class neighbourhood, had a population of 524 students and is a part of the Toronto District School Board. The sample is a grade four and five split class comprised of eight grade five students and 17 grade four students with a gender breakdown of 11 females and 14 male students. Of the grade five students three of them were males and five females, and within the fourth grade there were 6 females and 11 males. The age of the sample ranged from eight to ten years old with a mean age of 9.25 years. Of the 25 students in this class, one student was considered a minority and one student was born outside of Canada.

\subsection{Instrument and Procedure}

For the purposes of data collection a survey (see Appendix) was administered to the sample described above. This instrument was a researcher-created document, and as such has certain limitations relating to reliability and validity. The instrument was created after consulting the literature on student perception of curriculum and was designed to specifically cater to the sample of convenience used for this research proposal. The survey asked students to agree or disagree with 21 statements that represented four different categories: citizenship, better future, curriculum and academic performance. After receiving Internal Review Board approval for the project, the student teacher/action researcher administered the paper and pencil survey to the entire class in the fall of the school year. Students were provided with a brief explanation that the survey was anonymous and voluntary and the purpose was to 
collect their honest opinions on the topic of educational purpose. All but one student chose to complete the survey therefore the final sample consisted of 24 students.

\section{Results}

The results gleaned from the student survey supported the authors' assumption that elementary students are able to articulate their attitudes and beliefs surrounding the role of school and education. Survey questions were developed from four central themes; school for the purpose of citizenship, school for the purpose of building a better personal future, attitudes towards curriculum, and student attitudes of their own academic performance. Students overwhelmingly agreed that school should play a large role in their ability to become quality citizens. They also agreed that their community, country, and the world at large would be better places because of education. Responses also support that students believe that school is a means to greater future success and happiness (see Table 1). Student attitudes towards their own personal academic outlook and performance elicited only slightly more positive than negative responses. However, students were mostly negative when asked about their thoughts on curriculum; explained as what they learn within the classroom (see Table 2). From a curriculum perspective students seem to be dissatisfied with the subjects and topics that are presented in school.

Table 1: Educational Purpose

\begin{tabular}{lll}
\hline Question Prompt: & Agree & Disagree \\
\hline Education is a means to a better future & $85 \%$ & $15 \%$ \\
Schools contribute positively to citizenship & $82 \%$ & $18 \%$ \\
\hline
\end{tabular}

Table 2: Student Attitudes

\begin{tabular}{lll}
\hline Question Prompt: & Agree & Disagree \\
\hline Attitude toward academic performance & $63 \%$ & $37 \%$ \\
Attitude toward curriculum & $44 \%$ & $56 \%$ \\
\hline
\end{tabular}

\section{Discussion}

This action research set out to inform this student teacher candidate about student perspective regarding the goals and ideals of their education. The results succeeded in providing the researcher with valuable information specific to this sample and to further illustrate the importance of taking student perspective into account during curriculum development.

This study paints a picture of a sample torn between ideals. On one hand the students surveyed appear to highly value the idea of education contributing to their future and the 
future success of society, while on the other they display evidence of dissatisfaction with curriculum and their own academic performance. In terms of their feelings on what they perceive as the goals of education, the students outlined key points that relate back to both the literature and the theoretical framework.

From the literature (Zenov, Harmon, \& van Lier, 2008) it has been determined that two of the major forces driving education are to build better and more productive citizens, and to provide a foundation for students to lead happy and prosperous adult lives. Students in this sample shared the same ideals for their educational experience. When asked if they felt that school would lead to future success, better jobs, and whether they felt that school is an important part of their community, 95\% percent of the students surveyed agreed that these were key elements of why they go to school. This shared vision affirms what has, in principle and in theory, been set out as a major reason why schools exist.

This cohesion of ideals is encouraging considering that while initially creating the instrument, there was some concern that students at this level would not have a strong sense of their future selves in relation to their present school experiences. When specifically asked if they thought what they were learning in school now would affect them in the future, 21 of the 24 respondents agreed that this was the case. For a sample whose average age is 9.25 years old, they seemed to display strong feelings towards the role that school plays; not only for the present, but for the future as well.

In terms of what defines education, its purpose, and what we are ideally striving for within the classroom, the onus has been placed on adults to decide what school should mean for children. The notion that the purpose of education can and perhaps should exist as a circular narrative was a central theme in the literature (Atherton, 2009; Power, 2005; Zenov, Harmon \& van Lier, 2008). Within this premise, students, teachers and society can work in concert to inform one another's ideals, goals and desires for curriculum development. Even at the elementary level, students realize the importance education has in their life and in society. Perhaps a logical next step is for educators to inform students of the relation of the curriculum and their academic performance across all subjects to the greater benefits of society and their future.

For example, it is generally assumed that mathematics and language arts are the main priorities of educators. This is evidenced through the standardized testing and curriculum in place, as well as being a reflection of a long-held societal standard for education. This point will not be argued here, but it is interesting to note that $70 \%$ of students in this study did not consider these subjects as their favourites. This will not change the fact that mathematics and language arts will continue to be rigorously taught to all students. What can change is how educators, administrators, and policy makers approach the creation, and execution, of these subjects. If the goals and ideals in this particular instance are mismatched, then perhaps the utilisation of what students' desire in education may work towards better overall performance and a more enjoyable classroom experience.

Jerome Bruner (1996) wrote that "we need a surer sense of what to teach to whom and how to go about teaching it in such a way that it will make those taught more effective, less 
alienated, and better human beings" (p. 118). The results of this research point to the need to gain a surer sense of what students see as the goal of education and school. In the quest to improve how education is administered, there is room for student input on a variety of issues.

\section{References}

Abowitz, K. (2008). On the public and civic purposes of education. Educational Theory, 58(3), 357-376. http://dx.doi.org/10.1111/j.1741-5446.2008.00293.x

Atherton, J. S. (2011). Learning and Teaching:Constructivism in lerning [On-Line: UK] $\begin{array}{llll}\text { retrieved } 17 & \text { May } & 2012 \text { from: }\end{array}$ http://www.learningandteaching.info/learning/constructivism.htm

Baldwin, D. O. (2008). Teachers, students and pedagogy: Selected readings and documents in the history of canadian education. Markham, ON, Canada: Fitzhenry and Whiteside Limited.

Bruner, J. S. (1971). The relevance of education. Toronto: George J. McLeod Limited.

Bruner, J. S. (1996). The culture of education. USA: President and Fellows of Harvard College.

Bruner, J. S. (2006). In search of pedagogy: The selected works of Jerome S. Bruner (Vol. 1). New York: Routledge.

Childs, J. L. (1951). Educational philosophy of john dewey. In P. A. Schilpp (Ed.), The philosophy of John Dewey (pp. 419-443). New York: Tudor Publishing Company.

Gray, J., \& McLellan, R. (2006). A Matter of Attitude? Developing a Profile of Boys' and Girls' Responses to Primary Schooling. Gender and Education, 18(6), 651-672. Retrieved from ERIC database.

Jarvis, T., \& Pell, A. (2002). Changes in primary boys' and girls' attitudes to school and science during a two-year science in-service programme. Curriculum Journal, 13(1), 43-69. http://dx.doi.org/10.1080/09585170110115268

Parodi, D. (1951). Knowledge and action in Dewey's philosophy. In P. A. Schilpp (Ed.), The philosophy of John Dewey (pp. 229-242). New York: Tudor Publishing Company.

Power, C. (2005). Quo vadis? Education for what purpose? Social Alternatives, 24(4), 13-18. Retrieved from Academic Search Premier database.

Thomas, S., Smees, R., MacBeath, J., Robertson, P., \& Boyd, B. (2000). Valuing Pupils' Views in Scottish Schools. Educational Research \& Evaluation, 6(4), 281-316. Retrieved from Academic Search Premier database. 
Tymms, P. (2001). A Test of the Big Fish in a Little Pond Hypothesis: An Investigation into the Feelings of Seven-Year-Old Pupils in School. School Effectiveness and School Improvement, 12(2), 161-81. Retrieved from ERIC database.

West, A., Hailes, J., \& Sammons, P. (1997). Children's attitudes to the national curriculum at key stage 1. British Educational Research Journal, 23(5), 597. Retrieved from EBSCOhost.

Wink, J., \& Putney, L. G. (2002). A vision of Vygotsky. Toronto, ON: Allyn and Bacon.

Zenkov, K., Harmon, J., \& van Lier, P. (2008). Picture this: Seeing diverse youths' ideas about schools' purposes, supports, and impediments: Students from the "through eyes" project. Multicultural Perspectives, 10(3), 162-166. http://dx.doi.org/10.1080/15210960802198159

\section{Appendix Student Survey}

Instructions

1. Begin by circling your grade, gender and age.

2. Read each statement carefully.

3. Circle whether you agree or disagree with the statement.

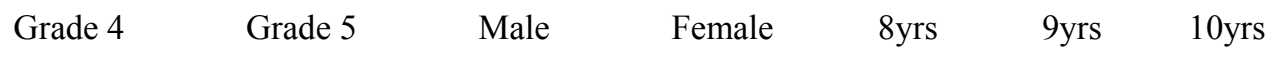


$\sim$ School makes me think I am smart.

Disagree

\#School is helping me become a better person.

Agree Disagree

I work hard on my schoolwork when I am in class.

Agree Disagree

${ }^{\wedge}$ The topics I study are interesting.

Agree

Disagree

\#If I do well in school now I will be successful later on in life.

Agree

Disagree

\#The things I am learning now will affect me in the future.

Agree

Disagree

${ }^{\wedge}$ There are many things I would rather be learning about.

Agree

Disagree

*School is an important part of my community.

Agree

Disagree

*School helps to make the world a better place.

Agree

Disagree

\#Being educated will help me get a better job.

Agree

Disagree

*Going to school helps make me a better citizen.

Agree

Disagree

${ }^{\wedge}$ The subjects I learn about in school are important to me.

Agree

Disagree

\#I will be unsuccessful in life if I do poorly at school.

Agree

Disagree

$\wedge^{\wedge}$ Math and language arts are two of my favourite subjects.

Agree

Disagree

$\sim$ I spend a lot of time at home working on school.

Agree

Disagree

*Canada will be a better place because of what I am learning at

Agree

Disagree school.

\#My future happiness depends on me doing well at school.

Agree

Disagree

$\sim$ The schoolwork I am required to complete is difficult.

Agree

Disagree

$\sim$ Getting good grades is important to me.

Agree

Disagree

*Education helps to make a difference in the world.

Agree

Disagree

${ }^{\wedge}$ I would like to have more input on what I learn in school.

Agree

Disagree 
Categories- for analysis purpose only (these were not visible to students)

*Citizenship, \#Better Future, ${ }^{\wedge}$ Curriculum, $\sim$ Academic Performance

\section{Copyright Disclaimer}

Copyright reserved by the author(s).

This article is an open-access article distributed under the terms and conditions of the Creative Commons Attribution license (http://creativecommons.org/licenses/by/3.0/). 